\title{
Design and Implementation of Satellite-Based Networks and Services for Ubiquitous Access to Healthcare
}

\author{
Georgi Graschew, Theo A. Roelofs, Stefan Rakowsky and Peter M. Schlag \\ Surgical Research Unit OP 2000, Experimental and Clinical Research Centre ECRC, \\ Max-Delbrück-Centre for Molecular Medicine and Charité - University Medicine Berlin, \\ Charité Campus Berlin-Buch, Lindenberger Weg 80, D-13125 Berlin
}

Germany

\section{Introduction and Background}

Telemedicine describes the use of Information and Communication Technologies (ICT) for the delivery of medical services. It aims at equal access to medical expertise irrespective of the geographical location of the person in need. New developments in ICT have enabled the transmission of medical images in sufficiently high quality that allows for a reliable diagnosis to be determined by the expert at the receiving site (Pande et al., 2003; Lacroix et al., 2002). Through Telemedicine patients can get access to medical expertise that may not be available at the patients' site. Networks for Telemedicine enable the integration of distributed medical competence and contribute to the improvement of the quality of medical care, to the cost-effective use of medical resources and to quick and reliable decisions.

For optimal performance of telemedical applications, the networks and communication tools used must be optimised for medical applications, both with respect to the Quality-of-Service (QoS, a set of parameters characterising the performance of the communication channel per se, such as transmission bandwidth, delay, jitter, data loss, etc.) as well as to the Class-ofService (CoS; a set of terms specifying the medical services offered in the network, like Telesurgery, Telepathology, Telesonography, Tele-Teaching, -Training \& -Education, etc.).

The use of specifically designed networks for telemedicine (distributed medical intelligence) contributes to the continuous improvement of patient care. Experience over the last decade has shown that the goals of Telemedicine are not automatically reached by the introduction and use of singular new technologies per se, but rather require the implementation of integral services.

At the same time, however, these innovative developments in ICT over the last decade bear the risk of creating and amplifying a digital divide in the world, creating a disparity in the quality of life, e.g. between the northern and the southern Euro-Mediterranean area (Graschew et al., 2003a; Dario et al., 2005; Graschew et al., 2004a). In recent years different projects have demonstrated how the digital divide is only one part of a more complex 
problem: the need for integration. (Wootton et al., 2005; Rheuban \& Sullivan, 2005; Graschew et al., 2003b; Graschew et al., 2002).

\section{Methodology}

During the last years OP 2000 (Operating Room of the future) has designed, developed and validated various modules for interactive telemedicine services (Schlag et al. 1999; Graschew et al. 2000). One of the key elements is the interactive telecommunication module WoTeSa / WinVicos: WoTeSa, a dedicated Workstation for Telemedical applications via Satellite that uses the communication software WinVicos (Wavelet-based interactive Video communication system).

WoTeSa is a PC with sufficient processing capacity ( $\geq 3 \mathrm{GHz}$ Pentium IV, $\geq 512 \mathrm{MB}$ RAM), one or more Osprey video capture boards (Osprey 100 or Osprey 500), a camera with composite and s-video outputs as live source (e. g. Canon VC-C4); a second camera as document camera for transmission of non-digital images; standard headset or microphone with small loudspeakers. The different video inputs of the Osprey video capture card can be used for direct connection to various medical video sources. WoTeSa thus serves quasi as a medical video hub. It is noteworthy that WoTeSa is a dedicated workstation and yet it can be realised with off-the-shelf components, thus making it readily available and at the same time very flexible and adaptive.

WinVicos is an all-software high-quality interactive video communication system, supplying real-time video, still-image and audio-transmission. WinVicos is especially designed for telemedical applications (e.g. telesurgery, teleradiology, telepathology) using a hybrid speed-optimised wavelet-codec that is based on the concepts of Partition, Aggregation and Conditional Coding (PACC; Patent DE 19734542 A1 from "Deutsche Telekom", Darmstadt, Germany). In contrast to most mainstream video coding systems that are mostly optimised for cinema and home entertainment, the PACC codec does not employ motion estimation but maximises the frame resolution to allow for maximal details to be visualised. WinVicos communicates IP-based and allows for online scaling of the transmission parameters (bit rate, frame rate and frame size from $128 \times 96$ up to $640 \times 480$ pixel). It supports both point-to-point and multipoint communication scenarios. Besides high quality live video transmission using moderate bandwidths $(0.5-1 \mathrm{Mbit} / \mathrm{s})$ it also allows for still-image transmission. WinVicos is very easy to use: there is a main user interface that is sufficient for the standard actions of the user. This includes calling the video conference partner via a telephone book, adjustment of both local and remote transmission parameters, as well as speaker and microphone volume control (see Fig. 1).

In both the video windows and the still-image windows WinVicos supports the use of common cursors shared by the conference partners. As WinVicos is an all-software system not only the implementation of other video codecs can be readily realised, but also a continuous performance improvement is supported to keep up with recent developments in the field. The most recent version of WinVicos also supports the transmission of video streams in full high definition (HD) resolution. Further readings on WoTeSa and WinVicos can be found in the literature (Graschew et al., 2001).

Other telemedicine systems are used e.g. for tele-ultrasound in rural areas where telementoring by live videoconferencing allowed to guide the ultrasound technician to record additional images of the patient ( $\mathrm{O}^{\prime} \mathrm{Neill}$ et al., 2000) for clinical assessment of 
pediatric burns which showed a good agreement between the face-to-face consultation and seeing the patient via videoconference (Smith et al., 2004) and for home telecare services likely to improve quality of health services (Guillen et al., 2002). Other systems are described in Sable 2002; Latifi et al., 2004, Eadie et al., 2003.

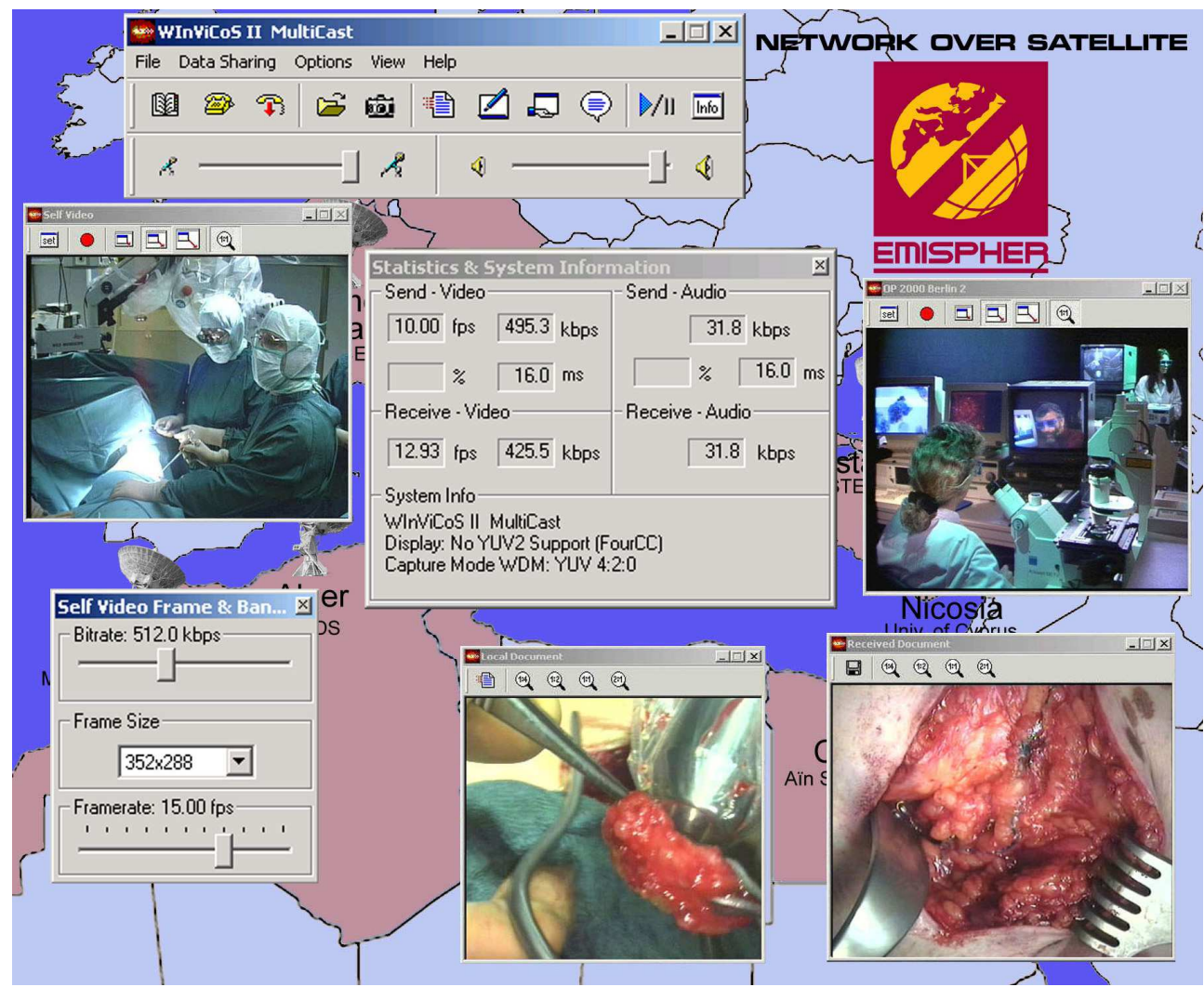

Fig. 1. WinVicos main user interface (top): two live video windows (top) and two still-image windows (bottom), online flexible adjustment of transmission parameters (bottom left), transmission performance can be monitored online (centre).

\section{Satellite-based Networks and Services}

OP 2000 has been a prominent partner in various telemedical networks using satellite-based technology for the deployment of services for interactive video communication and medical telepresence (Graschew et al., 2009). In the following, four projects will be described in which WoTeSa / WinVicos have been used as interactive tool for real-time telemedical application services and e-learning scenarios. 


\subsection{Generic Advance Low-cost trans-European Network Over Satellite - GALENOS}

In cooperation with: Eutelsat (F), Nortel Dasa, (D), Alcatel Space Industries (F), Telespazio (I), MEDSAT (F), NCSR Demokritos (Gr); financially supported by the European Union (EU).

In the GALENOS project a European competence network via satellite, dedicated to telemedical applications, has been realised (Graschew et al., 2001). Owing to the participation of industrial partners in integrating the communication network and getting satellite transmission capacity available, several telemedical services (e.g. offline access to archived data, live consultation of experts, tele-teaching, etc.) have become available in a unified and low-cost technology. This possibility to get support from external experts, the improvement of the precision of the surgical treatment, and last but not least, online documentation and hence improved analysis of the available data on a patient, contributes to a continuous improvement in treatment and care of patients.

The trans-European communication network over satellite provides various collaborative services and applications, avoiding the use of specific technologies, thus promoting a wide availability. Furthermore, the network exhibits inter-operability with previously existing telecommunication networks. The network offers up to $2 \mathrm{Mbit} / \mathrm{s}$ interfaces with satellite link and covers a total of 14 clinics in Bulgaria, France, Germany, Greece, Italy and Tunisia. Access to the local area network (LAN) at each site is also provided for the exchange of patient data, medical images, videoconferencing, etc. Substantial reactivity and technical flexibility allow treatment protocols, adapted to the patient's pathology, in the shortest time. The GALENOS network enables physicians not only to receive virtual "classical" hands-on medical training, but also trains them in using the state-of-the-art communication-, videoand computer-technologies needed for collaborative work in a network of distributed medical intelligence (interactive Teleteaching). Such distributed medical intelligence in the competence network enables e.g. local physicians or local hospitals that are confronted with unexpected test results to get online advice from the nearest academic hospital (intraoperative radiological Teleconsultation). It also becomes possible to perform intraoperative Telepathology where, after a biopsy has been taken and a slice has been prepared, this sample is put under a remotely-controllable, camera-equipped microscope and the diagnosis is then formulated by a remote expert. Or intraoperative Teleradiology, where anytime during the operation, the surgeon can access all the preoperative radiological data (like X-ray, CT, MRT, etc.) and discuss it with the radiologist in real-time.

\subsection{Disaster Emergency Logistic Telemedicine Advanced Satellites System - DELTASS}

The DELTASS Consortium consists of: Centre National D'Etudes Spatiales (F), MEDES (Institut de Médecine et de Physiologie Spatiales (F), SPACEBEL (B), Alcatel Space Industries (F), EADS - DORNIER (European Aeronautic Defence and Space Company (D), EADS - MS\&I (European Aeronautic Defence and Space Company - Matra Systémes \& Information (F), and Surgical Research Unit OP 2000 at Charité (D).

The DELTASS project was funded by the European Space Agency (ESA) as part of the ARTES-5 programme (Advanced Research in Telecommunications Systems).

Further general information on the DELTASS project can also be found at: http://telecom.esa.int/telecom/www/object/index.cfm?fobjectid=750. 
In the DELTASS-project (Graschew et al., 2008) a disaster scenario was analysed and an appropriate telecommunication system for effective rescue measures for the victims was set up and evaluated. Satellite-based systems are well suited for these circumstances, where generally ground infrastructures are partly or even totally destroyed. In such situations, even on a large geographic area or isolated area, space-based services can be easily and quickly deployed. DELTASS demonstrates operational performance of various services, covering the different aspects/phases of disaster emergency medicine. According to these phases, the DELTASS system is made up of the various corresponding subsystems (Fig. 2):

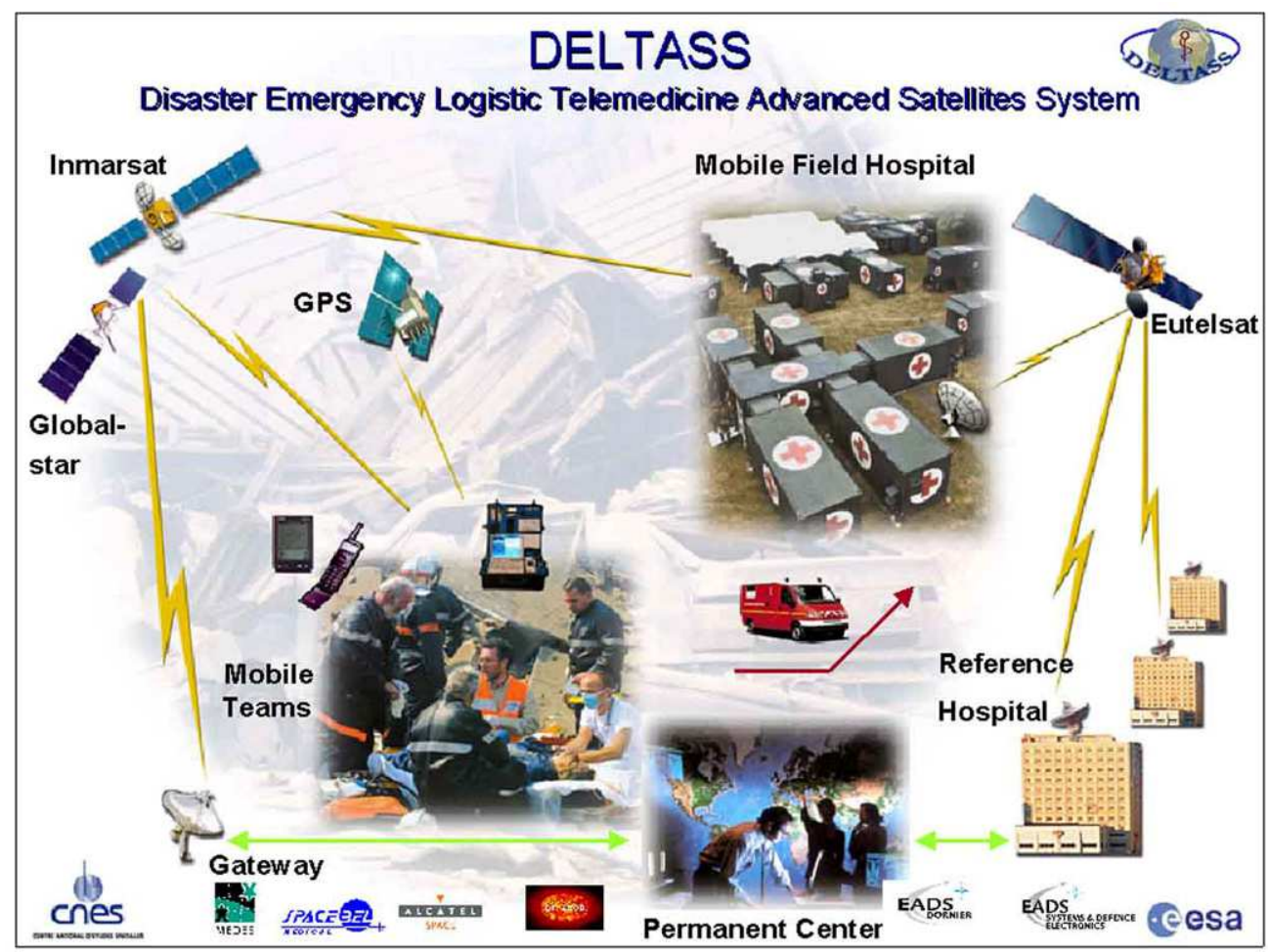

Fig. 2. DELTASS System Architecture: Mobile Teams, Permanent Centre (PC), Mobile Field Hospital (MFH) and Reference Hospital (RH) are interconnected via several satellite systems with different bandwidths. Additionally, terrestrial communication channels support the data exchange between the PC and the RH.

\section{Mobile Teams}

Mobile teams are deployed on the disaster site for search, identification, triage and evacuation of victims. They communicate with the coordination- and medical- teams located in Permanent Centre or Mobile Field Hospital via low-rate (Globalstar, $9.6 \mathrm{kbps}$ ) and medium-rate (Inmarsat, $64 \mathrm{kbps}$ ) satellite telecommunication systems. Their positions are tracked via the established Global Positioning System (GPS satellite system). 


\section{Permanent Centre}

The Permanent Centre is located outside the disaster area. The Permanent Centre constitutes a new element in the architecture of support systems for disaster emergencies and is unique to the DELTASS system. In conventional set-ups the mobile teams at the disaster site are coordinated and supported by the staff of a Mobile Field Hospital deployed at or close to the disaster site. However, complete deployment of such a Mobile Field Hospital takes at least $\sim 6$ hours, usually $\sim 12$ hours, and consequently the activities of mobile teams in these first, highly critical hours, are ill-coordinated and far from optimal. To improve this bottleneck, DELTASS has a designated Permanent Centre that is in control of coordination and medical support to the mobile teams from time zero on. The Permanent Centre is equipped with terrestrial gateways to the Globalstar and Inmarsat satellite systems through which it receives all data from the mobile teams. It coordinates all actions of the mobile teams and manages all medical and logistic data, thus assuring efficient operation during the first critical phase. All data received at the Permanent Centre are processed, appropriate Reference Hospitals (RH; see below) are identified and the logistic and medical data are transferred to these $\mathrm{RH}$ via terrestrial telecommunication links.

\section{Mobile Field Hospital (MFH)}

A Mobile Field Hospital (MFH), which will be deployed at or close to the disaster site, provides all activities related to the co-ordination of the mobile teams on the disaster site, the victims' medical triage, reception, first aid treatment, conditioning for transportation, further medical expertise for some patients by teleconsultations between MFH and Reference Hospital(s).

\section{Reference Hospital (RH)}

The Reference Hospital(s) (RH), located outside of the disaster area, acts as an expert centre by providing telemedical services to the MFH using the high-bandwidth satellite link (VSAT, $2 \mathrm{Mbps}$ ). These services consist of off-line and on-line telediagnosis, access to external medical databases, as well as real-time interactive telemedical services such as live teleconsultations, live telesonography, intraoperative virtual reality simulation and interactive telemicrobiology (see Figs. 3 and 4).

Statistics show that in cases of disaster emergency medicine, approx. $40 \%$ more amputations are performed, as compared to normal situation. One of the aims of providing live second opinion by remote experts is to reduce this number of unneeded amputations, manipulations and subsequent complications substantially, by expert support during triage, diagnosis and medical treatment.

These interactive telemedical services between the MFH and the $\mathrm{RH}$ are realised using a dedicated WoTeSa (Workstation for Telemedical Applications via Satellite) with the communication software WinVicos (Wavelet-based interactive Video communication system). WoTeSa/WinVicos combines the user-friendliness and flexibility of IP-based communication protocols with the security and sufficiently-high quality of the live video transmission at a satellite bandwidth of only up to 2 Mbps. Medical experts at the RH support the medical treatments in the MFH and enable a quick and reliable decision concerning treatment and/or evacuation of the patient/victim. In this way, the quality of the provided medical service during and after disaster emergencies is strongly improved. 
The performance of the DELTASS system has been shown during various full-size live demonstrations (http:// telecom.esa.int/telecom/www/object/index.cfm?fobjectid=6324).

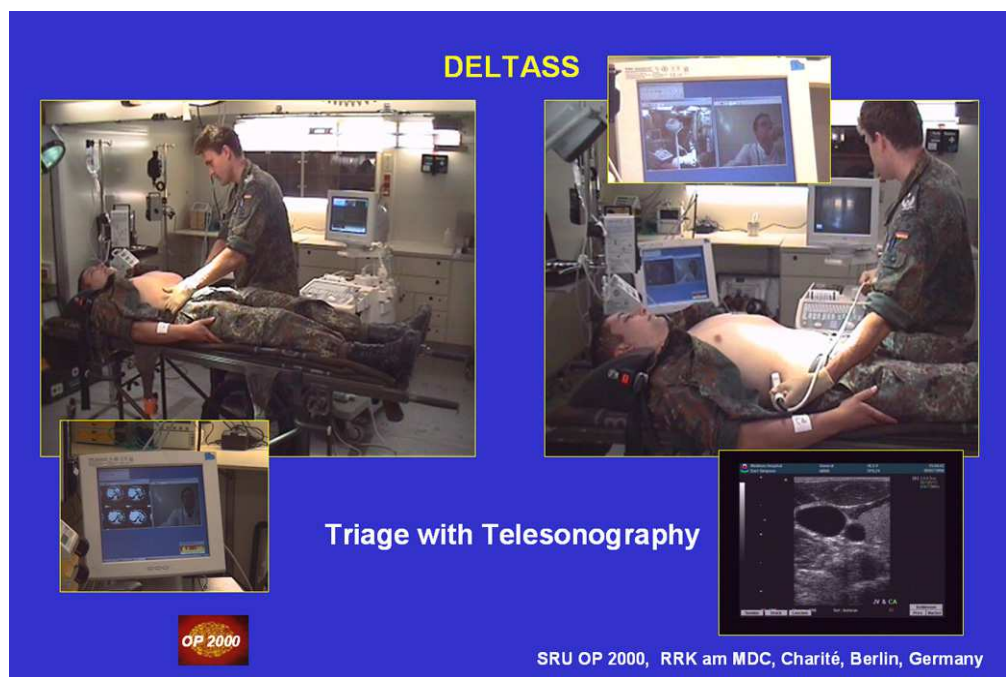

Fig. 3. Live Telesonography: The ultrasound video data stream (insert right bottom) is transmitted live via WoTeSa / WinVicos to the experts of the RH (insert right top). Additionally the signal of a room camera (e.g. for telementoring; insert right top) as well as further medical data (e.g. X-ray, CT, etc.; insert left bottom) can be transmitted live to the RH.

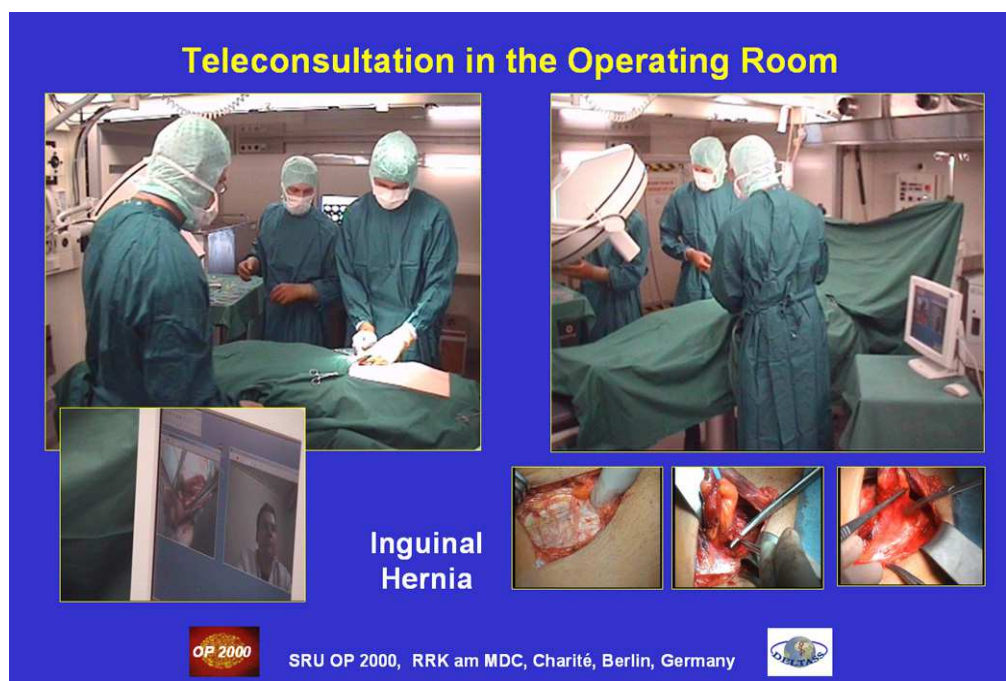

Fig. 4. Live Telesurgery of Inguinal Hernia: During the surgery the video data stream of a camera integrated in the centre of the surgical light can be transmitted live to the experts in the RH using WoTeSa / WinVicos (insert left bottom). In this way these experts receive a live video of the situs of surgery (inserts right bottom) and can advise the colleague in the MFH. 


\subsection{Medical Assistance for Ships - MEDASHIP}

Cooperating partners: D'Appolonia (I), AVIENDA (UK), Eutelsat (F), NCSR Demokritos (GR); co-funded by the European Union (EU) under the eTEN programme.

The main objective of the service developed by the MEDASHIP project is to supply integrated solutions for medical consultations on-board of ships (Graschew et al., 2004b). The satellite-based telemedicine services address both passenger ships and merchant vessels and are intended to provide passengers and crew members with an effective medical assistance in cases of emergency and in all those cases where the on board medical staff requires second opinion. During the validation phase the service was tested on board of three ships with the possibility to have it connected to three land medical centres. (Fig. 5).

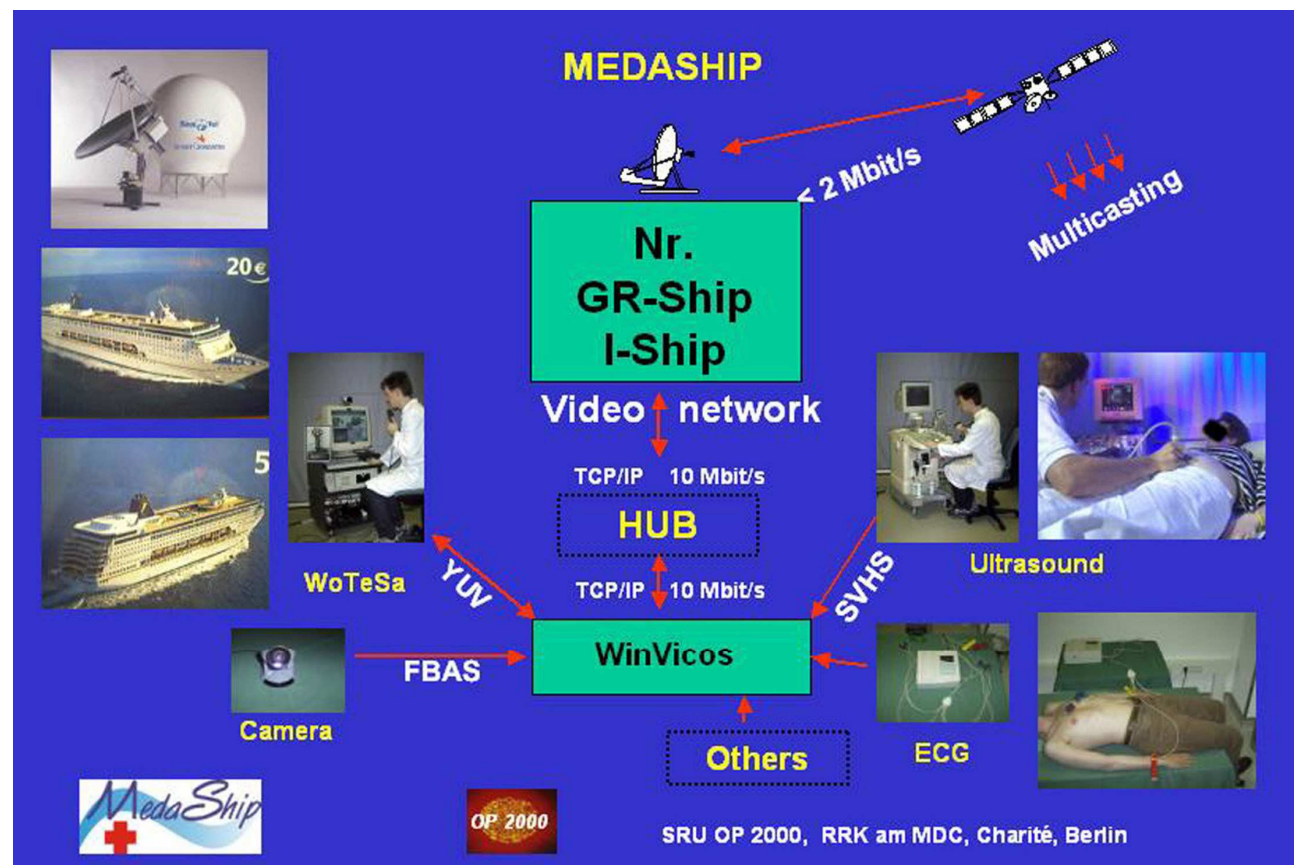

Fig. 5. Video network on-board of the ships: Video camera, ultrasound and electrocardiography equipment connected with the satellite modem via WoTeSa/WinVicos.

In addition to the standard medical equipment aboard the ships, two video cameras, an electrocardiograph (ECG) and an ultrasound (US) equipment are used. With this equipment the following telemedical services have been realised using satellite transmission at a bandwidth of $512 \mathrm{kbps}$ up to $1 \mathrm{Mbps}$ offering the required high quality of images and video transmission:

\section{Teleconsultation}

The live camera on-board of the ship can be used to transmit the image of the doctor who is leading the examination on-board of the ship or the image of the patient when being questioned by the land-based expert. It can also be used to show the land-based expert an 
injured part of the patient's body which he needs to see for his consultation. Thus a very realistic and effective live communication is possible.

\section{Electrocardiography}

The ECG system is connected to WoTeSa on board the ship and can be controlled by the physician from this workstation. Via application sharing software also the expert can control the ECG system from the land-based workstation. The main menu that includes all the functions of the ECG as well as the patient's ECG is transmitted to the expert. Thus the expert and the physician on board can jointly acquire and analyse the ECG report.

\section{Telesonography}

The S-video output of the US equipment is directly connected to the Osprey video capture board. Satellite transmission tests have shown that not only still images can be transferred but also live ultrasound investigations can be transmitted at 500-700 kbps (see Fig. 6).

With a document camera analogous patient data can be captured and digitised by WinVicos as a document. For example X-ray or CT-images can be captured from an illumination board and displayed locally and transmitted using this document camera function.

\section{Data Security}

Respect for patient confidentiality is a clear requirement in the MEDASHIP system and the level of privacy protection has been addressed throughout the MEDASHIP project. In MEDASHIP, from the telemedicine platform viewpoint, the following requirements should be taken into account to prevent abuse and to safeguard the privacy and confidentiality of managed clinical and personal information of the patients.

- Authentication: Monitoring and verifying all the accesses to the information. A control over the users should be carried out at each access to the system, by utilising the users' credentials (username and password) in order to verify that the user is who he/she claims to be.

- Encryption: Scrambling a sender's transmission according to an algorithm that the recipient then uses to unscramble and decipher the transmission. All the process is not visible to the user, the client software knows all it needs.

- Access control: Authorising access to specific and clearly identified resources to certain users based on their company responsibilities and the security classification of the resources.

- Integrity: Developing or utilising applications and data management software that is secure from unauthorised modification of their code.

- Confidentiality: Developing or utilising applications and data management software that is secure from disclosure to unauthorised persons or programs.

- Auditing and accounting system: Monitoring the system and maintaining records of system and user activity.

- $\quad$ Security policy: Establishing clear security policies with customers and end-users.

Unlike open network satellite equipment technologies Linkway uses a proprietary acquisition and synchronisation technique making signal interception and decoding virtually impossible. Data Security will also be assured by the coding algorithm of the WinVicos software. The transmitted data can only be decoded by this software. As one 
member owns the software licence this provides an initial level of data security through the licence distribution.

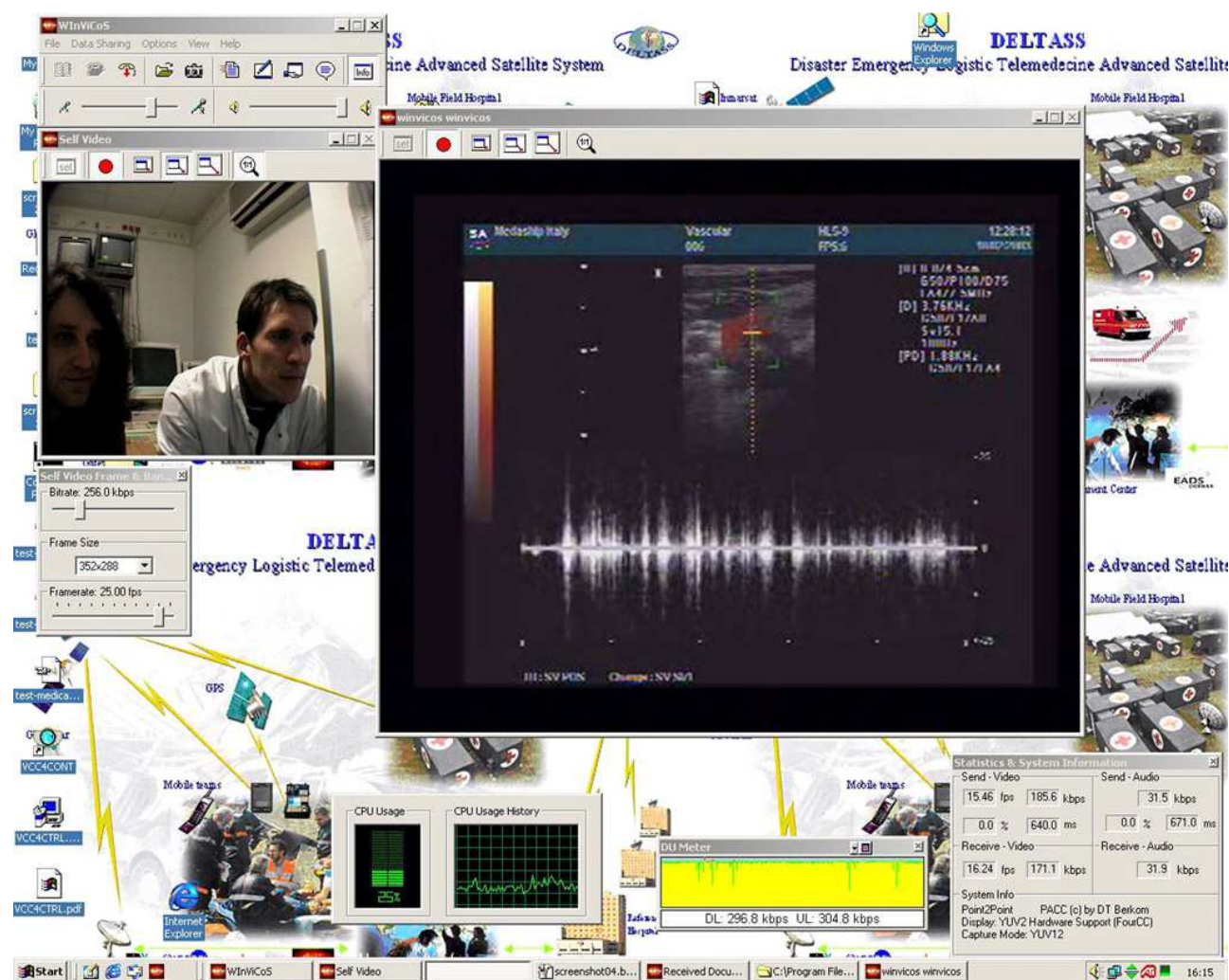

Fig. 6. Telesonography: the live signals of the ultrasound equipment on-board of the ship are transmitted to the reference hospital. A physician at Charité is consulting the ultrasound examination of a patient on board of the cruise ship.

Reduction of cost

The costs for emergency interventions for removing a passenger from the ship and hospitalisation abroad are not to be undervalued. The removal of a passenger in the Carribean can cost up to $\$ 11.000$ and the cost for hospitalisation can range from 500-1000 $€$ per day. Consequently, market trends force passenger shipping lines to offer services that help to improve the response to on-board clinical emergencies, improve the customer satisfaction and the companies' image.

\subsection{Euro-Mediterranean Internet-Satellite Platform for Health, medical Education and Research - EMISPHER}

In cooperation with: FMPC - Faculty of Medicine and Pharmacy of Casablanca, Morocco; ANDS - Agence National de Documentation de la Santé (Ministère de la Santé), Algiers, Algeria; Tunis - Faculty of Medicine of Tunis, Tunisia; ASU - Aïn Shams University, Cairo, 
Egypt; NIFRT - Nasser Institute for Research and Treatment (Ministry of Health and Population, MOHP), Cairo, Egypt; UCY - University of Cyprus, Nicosia, Cyprus; ISTEM Continuing Medical Education and Research Centre, University of Istanbul, Turkey; NCSR Demokritos, Athens, Greece; IsMeTT - Istituto Mediterraneo per i Trapianti e Terapie ad Alta Specializzazione, Palermo, Italy; CICE - Centre International de Chirurgie Endoscopique, Clermont-Ferrand, France; and Charité University Medicine Berlin, Germany; co-funded by the European Union (EU) under the EUMEDIS / MEDA programme.

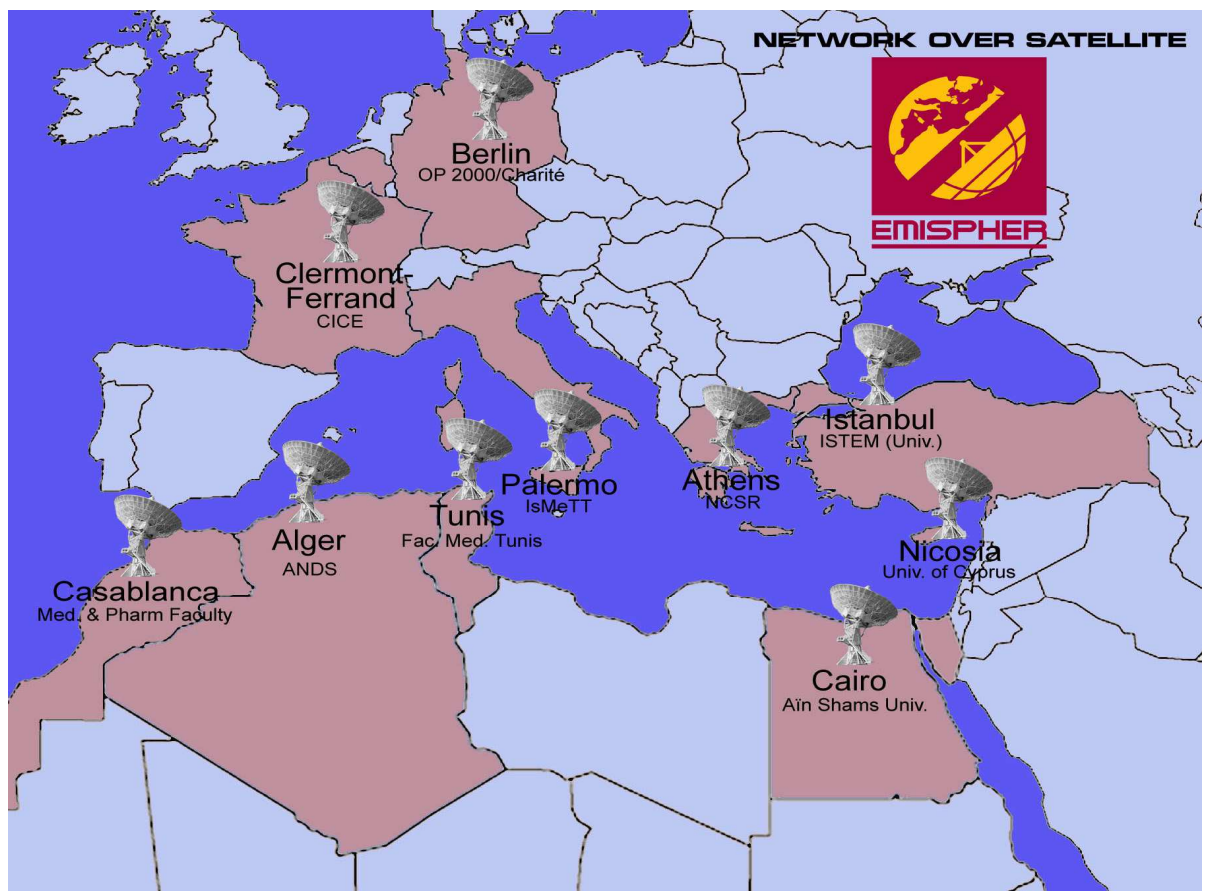

Fig. 7. Medical Centres in the EMISPHER Network

EMISPHER is dedicated to establish an equal access for most of the countries of the EuroMediterranean area to real-time and on-line services for healthcare in the required quality of service (see www.emispher.org). In the project an integrated Internet-Satellite platform has been set up on which three main areas of work have been realised: Virtual Medical University, Real-Time Telemedicine, and Medical Assistance (Graschew et al., 2005). The platform includes a bi-directional satellite network (up to $2 \mathrm{Mbps}$ ) between 10 Centres of Excellence in the Euro-Mediterranean region (Morocco, Algeria, Tunisia, Egypt, Cyprus, Turkey, Greece, Italy, France and Germany; see Fig. 7). For dissemination of the achieved results and for maximising its impact, EMISPHER has organised international conferences at each of the Mediterranean partner sites. 
The EMISPHER Virtual Medical University

The formation and operation of the EMISPHER Virtual Medical University (EVMU) for elearning (teleteaching) is one of the main efforts in the project. The EVMU uses real-time broadcast of lectures, live surgical operations and pre-recorded video sequences etc., as well as web-based e-learning applications. The target population of the EVMU is comprised of medical students (both undergraduate and postgraduate) hospital staff, general practitioners and specialists, health officers and citizens.

Each of the leading medical centres provides didactical material and modules for synchronous and asynchronous e-learning in their medical specialties. The central gateway to EVMU is the project's website: www.emispher.org.

Some of the multimedia teaching material needs to be presented in real-time. Live transmission of surgical operations from operating theatres, lectures, etc. from one site to one or several sites simultaneously (point-to-point or multipoint) are possible in the network between the 10 partners (Fig. 8).

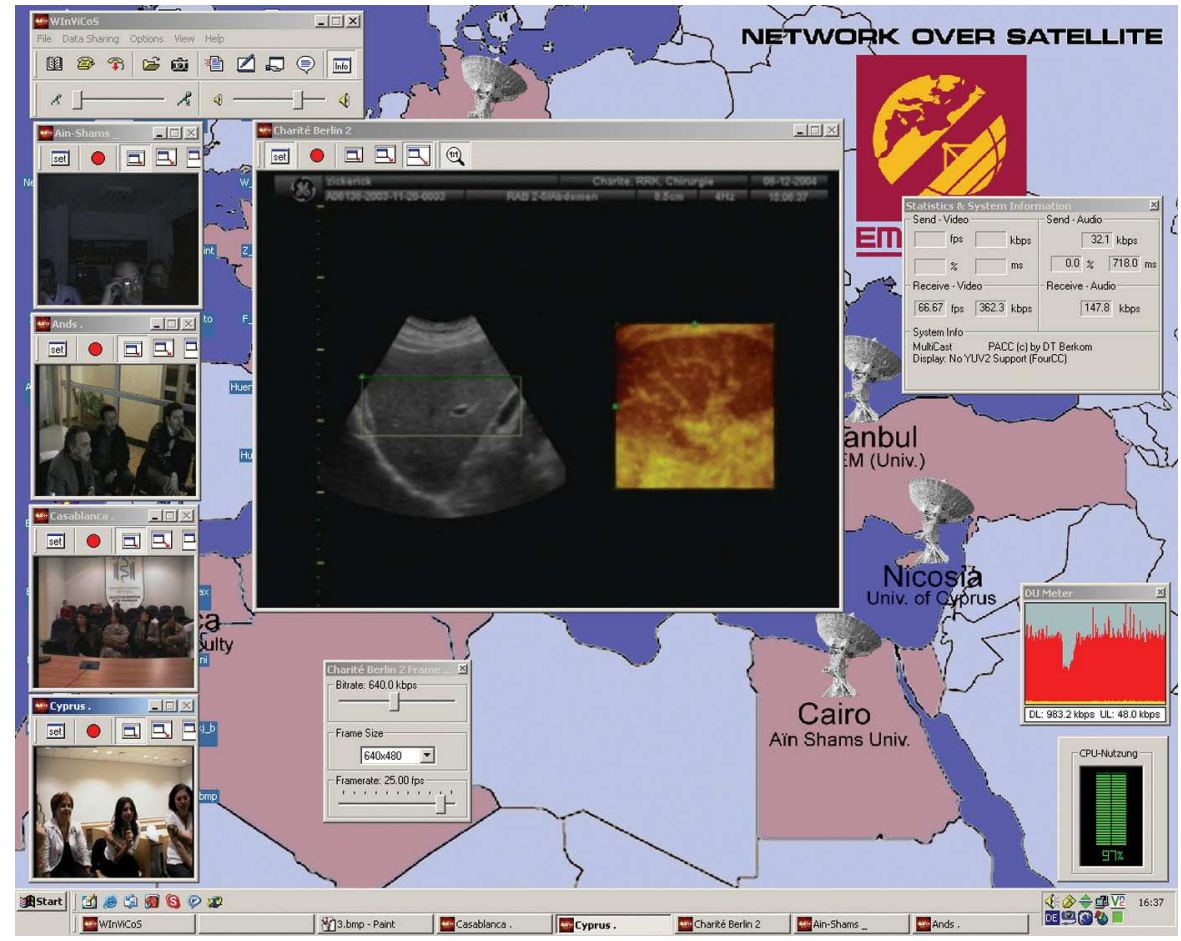

Fig. 8. Interactive multipoint e-learning session with transmission of live ultrasound video data from Charite (Berlin) to Ain Shams University (Cairo), Agence Nationale de Sante (Algiers), Faculté de Medecine et de Pharmacie (Casablanca) and University of Cyprus (Nicosia).

\section{Real-Time Telemedicine}

EMISPHER has set up a satellite-based network using the combined WoTeSa and WinVicos modules for real-time telemedicine. In the field of real-time telemedicine the following 
categories of applications are offered: second opinion, teleteaching \& teletraining (demonstration and spread of new techniques), telementoring (enhancement of staff qualification), and undergraduate teaching courses and optimisation of the learning curve. The leading medical centres in the project provide expertise in the following medical fields: open and minimally-invasive surgery, multi-organ transplantation, endoscopy, pathology, radiology, interventional imaging, neurology, infectious diseases, oncology, gynaecology and obstetrics, reproductive medicine, etc. These real-time telemedical applications contribute to improved quality of patient care and to accelerated qualification of medical doctors in their respective specialty. The main target audience are specialist doctors (Fig. 9).

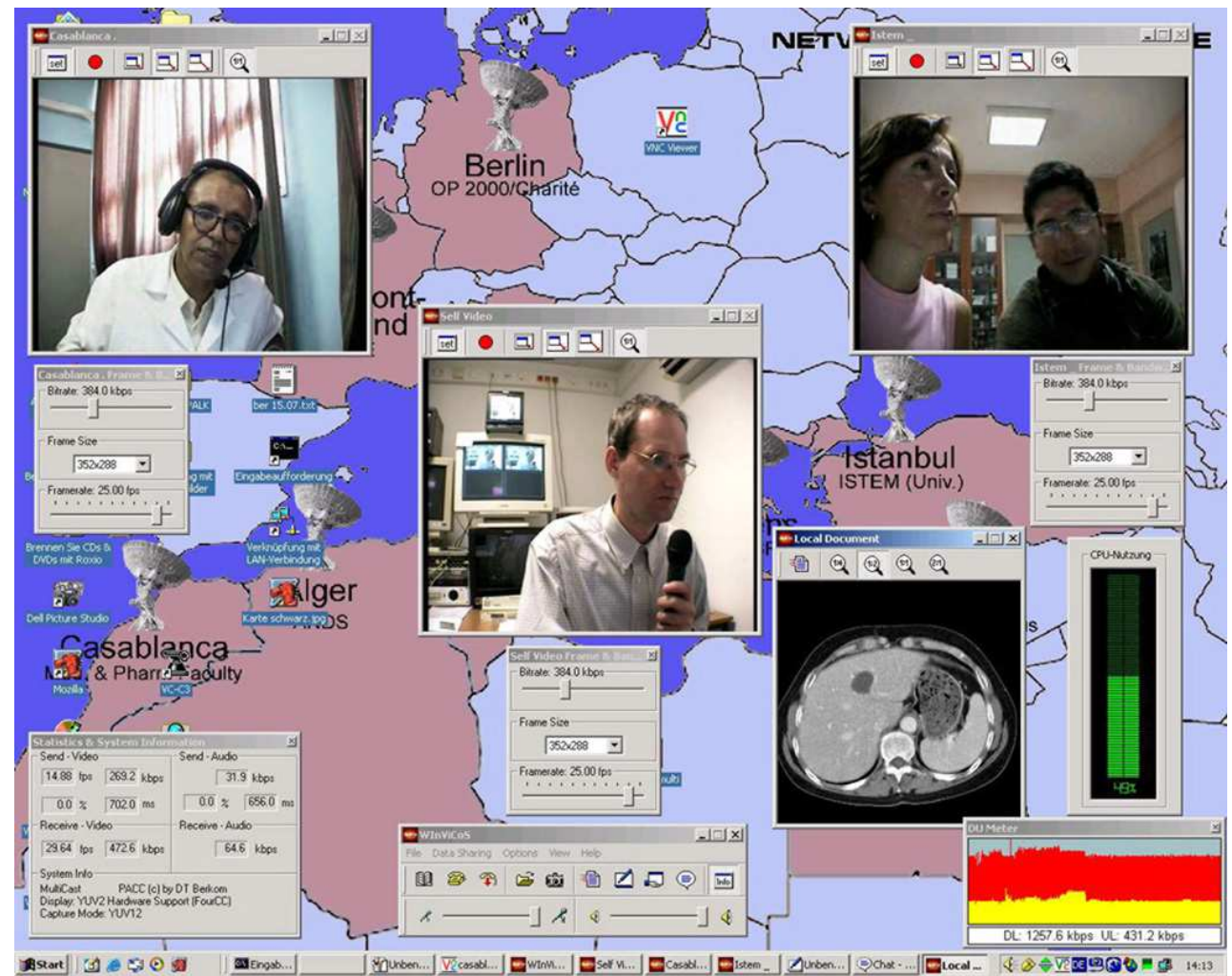

Fig. 9. Interactive multipoint radiological teleconsultation in EMISPHER. Experts from different centres interactively discuss radiology results from a particular patient case.

\section{Medical Assistance}

The third field of service operated in EMISPHER is medical assistance. As tourism constitutes a substantial economical factor in the Mediterranean region and because of the increasing mobility of the population, continuity of care through improved medical assistance is of major importance for improved healthcare in the Euro-Mediterranean region. Introduction of standardised procedures, integration of the platform with the various local communication systems and training of the medical and non-medical staff 
involved in the medical assistance chain allow for shared management of files related to medical assistance (medical images, diagnosis, workflow, financial management, etc.) and thus for improved care for travellers and expatriates.

\section{User Evaluation}

Two types of evaluation were performed for the EMISPHER satellite-internet platform and the services delivered from the platform. Firstly, the evaluation of all technical aspects of the platform and connecting services (WinVicos and MEDSKY) and secondly the evaluation of the operational elements of the system meeting the medical user requirements.

Overall point-to-point connections were successful with normal delays ( $650 \mathrm{~ms})$. Realised maximum bandwidths for symmetric point-to-point connections are 512-640 kbps in each direction. Up to these bandwidths the video and audio streaming is smooth. When going beyond these settings frozen images and audio problems start occurring. For asymmetric video bandwidth allocation (for example for e-learning applications) the maximum bandwidth settings for good operation are $768 \mathrm{kbps}$ in one direction and $192 \mathrm{kbps}$ in the other direction. For multipoint connections between three sites the maximum bandwidth settings for good operation are 384, 384 and $512 \mathrm{kbps}$. If the results presented above are compared with the nominal bandwidths required for the various services, it is clear that the EMISPHER platform provides sufficient bandwidth for most of the telemedicine applications with smooth video and audio streams in sufficient resolution.

During the first months of full operation of the network continuous evaluations have been performed and user-feedback was collected. This resulted in the upgrade of the WinVicos telemedical communication software as well as various upgrades of the MEDSKY software platform. The valuable user feedbacks were taken into account and have lead to even improved functionalities of the system and thus improved quality of medical work.

This demonstrates that the satellite platform with WoTeSa/WinVicos telemedical stations is very suited for the envisioned variety of medical services and is easy to learn for a wide range of medical professionals from the various countries.

\section{Barriers and their possible solutions}

Although the market is promising and the technology ready (or nearly) to be used, the takeup and commercialisation of the telemedicine services is still uncertain due to a number of barriers:

External

- Decision-making in health is fragmented with respect to procurement policies, which hinders progression towards real integration.

- Establishing and building confidence with physicians takes time.

- It still seems that it will be a further 1-2 years before full deployment and therefore a critical mass can be built.

- How the services are packaged and attitudinal changes from within the health sector are also necessary.

- There are numerous organisational issues.

\section{Economic}

- It is difficult to predict the breakeven level of services and therefore to determine the minimum level of investment required for breakeven of the services. 
- There is a lack of investment in health and therefore significant investment is still required.

- Considerable investment in improved management, training and education of Legal personnel, re-designing of care and logistic processes is necessary.

- Ethical issues

- Regulatory framework issues

- Reimbursement issues

- Lack of standardisation

Technical

- Software development is still evolving.

- IP levels of connectivity are also required as a minimum.

- All the services need to be fully integrated into one platform.

In various pilot projects, the technology has been put in place, the necessary applications have been developed and it had been proved that it can be used successfully and meet the needs of its end users. Yet numerous trials and demonstrations carried out during the projects have also highlighted a certain number of issues that could potentially hinder the commercialisation process of e-services in the medical sector.

In fact, various market analysis reports prepared for the European Commission also insist on the fact that the telemedicine market growth will be dependent upon a number of vital conditions and enabling factors already noted above. It is generally accepted that four key action lines should be initiated in parallel: consolidation on the supply side, technical integration, investment on the demand side and "accompanying measures" that could be the enabling factors required to allow the health telematics market to achieve substantial and exponential growth.

Suggested solutions to overcome barriers

The solutions to such 'barriers' to commercialisation do not lie within the scope of the technology and appear to be generic to those 'up and running' tele-health activities worldwide. It is only in North America that new legislation has been introduced to respond to the particular needs of this practice and this legislation are not yet being applied on a federal level but rather on a state by state basis. However, the organisational and cultural aspects that must accompany any new form of practice need the input of other actors both on the governmental, legal and political scale. Tele-health is not a simple extension of current health systems and cannot be perceived as such.

Solutions to the "barriers" can be consolidated under the following three main categories:

- Awareness of telemedicine and tele-health as integral part of medical practice;

- The need for common standards and policies;

- The need for specific legislation.

\section{Conclusions and Perspectives: Virtual Hospitals}

Satellite-based networks and services are crucial to support ubiquitous access to healthcare. Appropriate enabling technologies must be deployed and interconnected via networks with 
an appropriate design. In this chapter we have presented WoTeSa/WinVicos as a flexible high-end module for real-time interactive telemedical services. Besides video communication in medically expedient quality, the provision of interactivity for the remote control of medical equipment is indispensable. Both video communication and interactivity require a (nearly) real-time mode of bi-directional interactions. Various examples have been given of particular networks and services that have been deployed, each to support medical telepresence in specific functional scenarios (GALENOS, DELTASS MEDASHIP and EMISPHER).

However, despite substantial improvements that have been realised, these developments bear the risk of creating and amplifying digital divides in the world. To avoid and counteract this risk and to fulfill the promise of Telemedicine, namely ubiquitous access to high-level healthcare for everyone, anytime, anywhere (so-called ubiquitous Healthcare or $\mathrm{u}$-Health) a real integration of both the various platforms (providing the "Quality-ofService", QoS) and the various services (providing the "Class-of-Service", CoS) is required (Graschew et al., 2002; Graschew et al., 2003b; Wootton et al., 2005; Rheuban \& Sullivan 2005; Graschew et al., 2006a). A virtual combination of applications serves as the basic concept for the virtualisation of hospitals. Virtualisation of hospitals supports the creation of ubiquitous organisations for healthcare, which amplify the attributes of physical organisations by extending its power and reach. Instead of people having to come to the physical hospital for information and services the virtual hospital comes to them whenever they need it. The creation of Virtual Hospitals ( $\mathrm{VH})$ can bring us closer to the ultimate target of u-Health (Graschew et al., 2006b).

The methodologies of $\mathrm{VH}$ should be medical-needs-driven, rather than technology-driven. Moreover, they should also supply new management tools for virtual medical communities (e.g. to support trust-building in virtual communities). VH provide a modular architecture for integration of different telemedical solutions in one platform (see Fig. 10).

Due to the distributed character of $\mathrm{VH}$, data, computing resources as well as the need for these are distributed over many sites in the Virtual Hospital. Therefore, Grid infrastructures and services become useful for successful deployment of services like acquisition and processing of medical images (3D patient models), data storage, archiving and retrieval, as well as data mining, especially for evidence-based medicine (Graschew et al., 2006c).

The possibility to get support from external experts, the improvement of the precision of the medical treatment by means of a real medical telepresence, as well as online documentation and hence improved analysis of the available data of a patient, all contribute to an improvement in treatment and care of patients in all circumstances, thus supporting our progress from e-Health and Telemedicine towards real u-Health. 


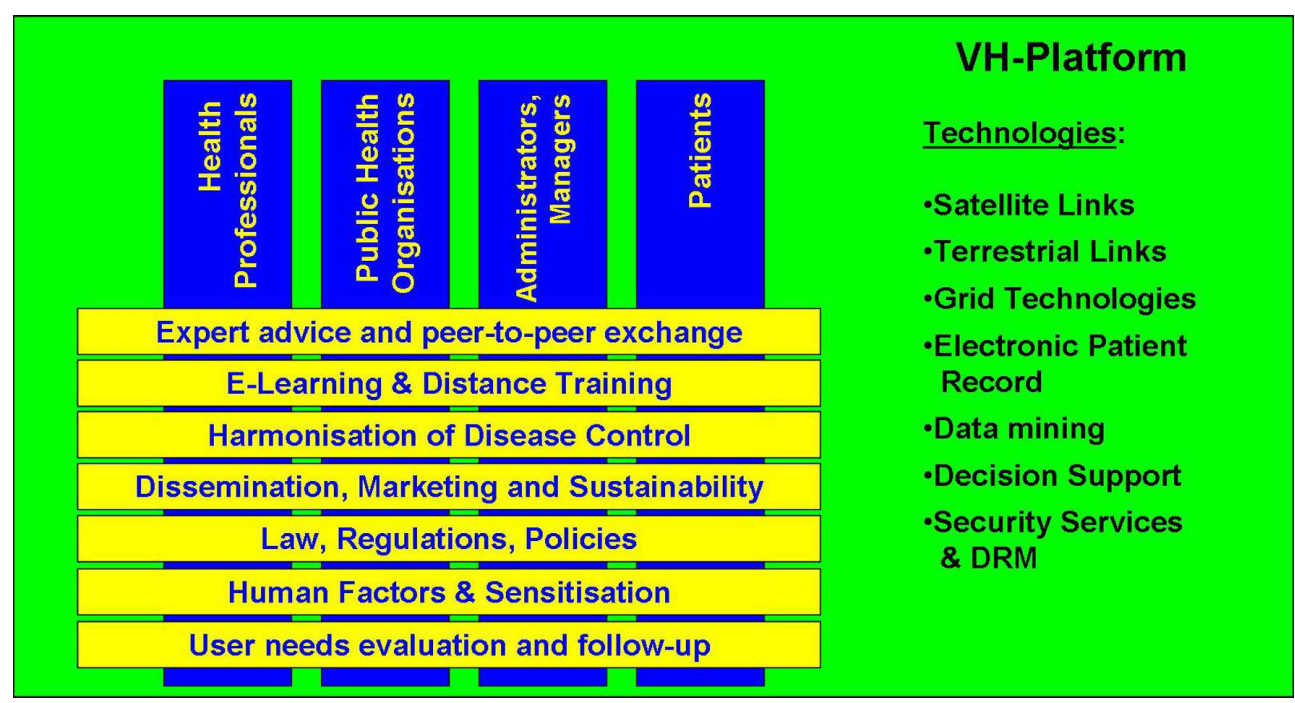

Fig. 10. Concept for the functional organisation of Virtual Hospitals (VH): The technologies of VH (providing the "Quality-of-Service", QoS) like satellite-terrestrial links, Grid technologies, etc. will be implemented as a transparent layer, so that the various user groups can access a variety of services (providing the "Class-of-Service", CoS) such as expert advice, e-learning, etc. on top of it, not bothering with the technological details and constraints.

\section{References}

Dario, C. et al. (2005). Opportunities and Challenges of eHealth and Telemedicine via Satellite. Eur J. Med. Res., Vol. 10, Suppl I, Proceedings of ESRIN-Symposium, July 5, 2004, Frascati, Italy, (2005), pp. 1-52.

Eadie, L.H. et al., (2003). Telemedicine in surgery. Br. J. Surg., Vol. 90, pp. 647-58.

Graschew, G. et al. (2000). Interactive telemedicine in the operating theatre of the future. J Telemedicine and Telecare Vol. 6, Suppl. 2, pp. 20-24.

Graschew, G. et al. (2001). GALENOS as interactive telemedical network via satellite, In: Optical Network Design and Management, Proc. of SPIE, Vol 4584, pp. 202-205.

Graschew, G. et al. (2002). Broadband Networks for Interactive Telemedical Applications, APOC 2002, Applications of Broadband Optical and Wireless Networks, Shanghai 16.17.10.2002, Proceedings of SPIE, Vol. 4912, pp. 1-6.

Graschew, G. et al. (2003a). Telemedicine as a Bridge to Avoid the Digital Divide World, 8 . Fortbildungsveranstaltung und Arbeitstagung Telemed 2003, Berlin, 7.-8. November 2003, Tagungsband, pp. 122-127.

Graschew, G. et al. (2003b). Telepresence over Satellite, Proceedings of the 17th International Congress Computer Assisted Radiology and Surgery, London, 25.-28.6.2003, International Congress Series, Vol. 1256, ed. H.U. Lemke et al., pp. 273-278.

Graschew, G. et al. (2004a). Interactive Telemedicine as a Tool to Avoid a Digital Divide of the World, In: Medical Care and Compunetics 1, L. Bos (Ed.), pp. 150-156, IOS Press, Amsterdam. 
Graschew, G. et al., (2004b). MEDASHIP - Medizinische Assistenz an Bord von Schiffen, In: Telemedizinführer Deutschland, ed. 2004, A. Jäckel (Ed.), Deutsches Medizin Forum, Ober-Mörlen, Germany, pp. 45-50.

Graschew, G. et al., (2005). Überbrückung der digitalen Teilung in der Euro-Mediterranen Gesundheitsversorgung - das EMISPHER-Projekt, In: Telemedizinführer Deutschland, ed. 2005, A. Jäckel (Ed.), Ober-Mörlen, Germany, pp. 231-236.

Graschew, G. et al., (2006a). VEMH - Virtual Euro-Mediterranean Hospital für Evidenzbasierte Medizin in der Euro-Mediterranen Region, In: Telemedizinführer Deutschland, Ausgabe 2006, A. Jäckel (Ed.), Medizin Forum AG, Bad Nauheim, Germany, pp. 233-236.

Graschew, G. et al., (2006b). New Trends in the Virtualization of Hospitals - Tools for Global e-Health, In: Medical and Care Compunetics 3, L. Bos et al. (Eds.) Proceedings of ICMCC 2006, The Hague, 7-9 June 2006, IOS Press, Amsterdam, pp.168-175.

Graschew, G. et al., (2006c). Virtual Hospital and Digital Medicine - Why is the GRID needed?, In: Challenges and Opportunities of HealthGrids, V. Hernandez et al. (Eds.) Proceedings of HealthGrid 2006, Valencia, 7-9 June 2006, IOS Press, Amsterdam, pp.295-304.

Graschew, G. et al., (2008). DELTASS - Disaster Emergency Logistic Telemedicine Advanced Satellites System - Telemedical Services for Disaster Emergencies. International Journal of Risk Assessment and Management Vol. 9, pp. 351-366.

Graschew, G. et al., (2009). New developments in network design for telemedicine. Hospital IT Europe, Vol. 2 No. 2, pp. 15-18.

Guillen, S. et al., (2002). User satisfaction with home telecare based on broadband communication. J. Telemed. Telecare, Vol. 8, pp. 81-90.

Lacroix, L. et al., (2002). International concerted action on collaboration in telemedicine: recommendations of the G-8 Global Healthcare Applications Subproject-4. Telemed. J. E-Health, Vol. 8, pp. 149-157.

Latifi, R. et al., (2004). Telepresence and telemedicine in trauma and emergency care management. Stud. Health Technol. Inform., Vol. 104, pp. 193-199.

O'Neill, S.K. et al., (2000). The design and implementation of an off-the-shelf, standardsbased tele-ultrasound system. J. Telemed. Telecare, Vol. 6, suppl 2, pp. 52-53.

Pande, R.U. et al., (2003). The telecommunication revolution in the medical field: present applications and future perspective. Curr. Surg., Vol. 60, pp. 636-640.

Rheuban, K.S. \& Sullivan, E. (2005). The University of Virginia Telemedicine Program: traversing barriers beyond geography. J. Long-Term Eff. Med. Implants, Vol. 15, pp. 49-56.

Sable, C. (2002). Digital echocardiography and telemedicine applications in pediatric cardiology. Pediatr-Cardiol. Vol. 23, pp. 358-369.

Schlag, P.M. et al., (1999). Telemedicine - The New Must for Surgery. Archives of Surgery Vol. 134, pp. 1216-1221.

Smith, A.C. et al., (2004). Diagnostic accuracy of and patient satisfaction with telemedicine for the follow-up of paediatric burns patients. J. Telemed. Telecare, Vol. 10, pp. 193198.

Wootton, R. et al., (2005). E-health and the Universitas 21 organization: 2. Telemedicine and underserved populations. J. Telemed. Telecare, Vol. 11, pp. 221-224. 


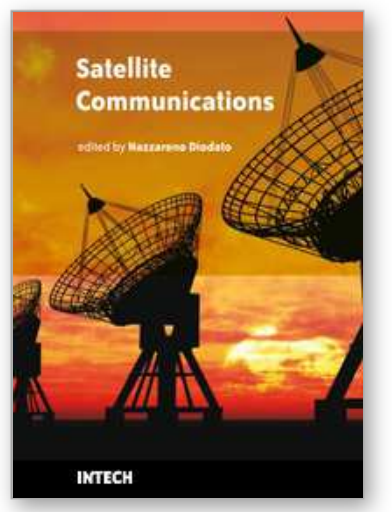

\author{
Satellite Communications \\ Edited by Nazzareno Diodato
}

ISBN 978-953-307-135-0

Hard cover, 530 pages

Publisher Sciyo

Published online 18, August, 2010

Published in print edition August, 2010

This study is motivated by the need to give the reader a broad view of the developments, key concepts, and technologies related to information society evolution, with a focus on the wireless communications and geoinformation technologies and their role in the environment. Giving perspective, it aims at assisting people active in the industry, the public sector, and Earth science fields as well, by providing a base for their continued work and thinking.

\title{
How to reference
}

In order to correctly reference this scholarly work, feel free to copy and paste the following:

Georgi Graschew, Theo A. Roelofs, Stefan Rakowsky and Peter M. Schlag (2010). Design and Implementation of Satellite-Based Networks and Services for Ubiquitous Access to Healthcare, Satellite Communications, Nazzareno Diodato (Ed.), ISBN: 978-953-307-135-0, InTech, Available from:

http://www.intechopen.com/books/satellite-communications/design-and-implementation-of-satellite-basednetworks-and-services-for-ubiquitous-access-to-healthca

\section{INTECH}

open science | open minds

\section{InTech Europe}

University Campus STeP Ri

Slavka Krautzeka 83/A

51000 Rijeka, Croatia

Phone: +385 (51) 770447

Fax: +385 (51) 686166

www.intechopen.com

\section{InTech China}

Unit 405, Office Block, Hotel Equatorial Shanghai

No.65, Yan An Road (West), Shanghai, 200040, China

中国上海市延安西路65号上海国际贵都大饭店办公楼 405 单元

Phone: +86-21-62489820

Fax: +86-21-62489821 
(C) 2010 The Author(s). Licensee IntechOpen. This chapter is distributed under the terms of the Creative Commons Attribution-NonCommercialShareAlike-3.0 License, which permits use, distribution and reproduction for non-commercial purposes, provided the original is properly cited and derivative works building on this content are distributed under the same license. 